\section{Normal Stress}

Jeffrey R. Keaton

Amec Foster Wheeler, Los Angeles, CA, USA

\section{Definition}

Normal stress is stress acting perpendicular or normal to a plane of interest or a reference plane. The stress tensor in a Cartesian coordinate system is represented by three normal stress components and six shear stress components. If a reference cube with orthogonal faces is rotated to a specific orientation in a stress field, the magnitudes of all the shear stress components become zero, and all the normal stress components become principal stresses.
In direct shear tests of soil or rock samples, a vertical load is applied to the sample while part of the sample is shifted horizontally relative to part of the sample which is held in position. The vertical load divided by the area of the sample is taken to be the normal stress of the test. Typically, the vertical load bears on a steel plate that has been manufactured to fit in the testing device to ensure that the load is applied uniformly over the surface of the sample.

\section{Cross-References}

$\checkmark$ Stress 